\title{
O conceito de ritual em Richard Schechner e Victor Turner:
} \section{análises e comparações}

\begin{abstract}
Resumo
O presente artigo busca apresentar um estudo comparado entre os conceitos de ritual apresentados da obra Performance e Antropologia de Richard Schechner, uma compilação de textos escritos por Schechner e organizados por Zeca Ligiéro, e na obra O Processo Ritual: Estrutura e Antiestrutura, de Victor Turner. Reconhecendo a importância do conceito de ritual para os estudos da performance desenvolvido por estes dois autores, pretendo, através do estudo comparado entre eles, discutir e analisar as singularidades deste conceito e dos autores ao defini-lo.
\end{abstract}

Palavras-chave: Ritual, Richard Schechner, Victor Turner, Performance

\section{Abstract}

This article seeks to present a comparative study between the concepts of ritual presented of the work Performance e Antropologia de Richard Schechner, a compilation of texts written by Schechner and organized by Zeca Ligiéro, and in the work O Processo Ritual: Estrutura e Antiestrutura, a translation of the text of Victor Turner. Recognizing the importance of the concept of ritual for performance studies developed by these two authors I intend, through the comparative study between them, discuss and analyze the singularities of this concept and of these authors to define it.

Key words: Ritual, Richard Schechner, Victor Turner, Performance

\section{Resumen}

Este artículo trata de presentar un estudio comparativo entre lo concepto de ritual presentados en los trabajos Performance e Antropologia de Richard Schechner, una recopilación de textos escritos por Schechner y organizado por Zeca Ligiéro, y O Processo Ritual: Estrutura e Antiestrutura, Victor Turner. Reconociendo la importancia del concepto de ritual para los estudios de performance desarrollados por estos dos autores, propongo, por el estudio comparativo entre ellos, discutir y analizar las singularidades de este concepto y de los autores lo definen.

Palabras clave: Ritual, Richard Schechner, Victor Turner, Performance

As linhas deste artigo estão dedicadas a um breve estudo comparado entre o conceito de ritual presente na obra O Processo Ritual: Estrutura e Antiestrutura de Victor Turner e aquele presente em Performance e Antropologia de Richard Sche-

1 Mestranda na Universidade Federal de Goiás na área de Performances Culturais sob orientação do Prof. Dr. Robson Corrêa de Camargo com bolsa CAPES. 
chner com traduções de textos de autoria de Richard Schechner e incluindo uma entrevista realizada com o mesmo. ${ }^{2}$

Partindo de amplos universos teóricos que lapidei o conceito de ritual apresentado por estes autores. Em Turner (1974) este conceito está implicado em diversas considerações acerca de seu trabalho antropológico, em Schechner (2012), está amalgamado no universo das performances.

Richard Schechner e Victor Turner, dois grandes autores de duas grandes áreas, o teatro e a antropologia, respectivamente. O leitor pode estar se perguntando: por que fazer um paralelo entre dois autores de áreas tão distintas? A resposta dá-se em dois substratos da biografia e igualmente na bibliografia destes autores. Uma destas questões é a relação interpessoal e profissional desenvolvida entre eles ao longo de suas carreiras. Eles leram e discutiram trabalhos um do outro, formularam críticas e revisaram seus próprios paradigmas através deste contato um com o outro. Isto ficará evidente em certos aspectos do conceito de ritual o qual pretendo desenvolver adiante a partir de suas perspectivas. O segundo ponto que me leva a desenvolver este estudo comparado é a questão de que para estes autores suas áreas de atuação não estão assim tão distantes. Schechner vem da tradição do teatro, mas logo se interessou pela antropologia, pela observação do outro, que não deixa de ser essencial para os artistas. Turner era um antropólogo que desde seu nascimento tinha à sua volta a aura do teatro, representada por sua mãe que era atriz, e quando começa a desenvolver seus trabalhos de campo percebe uma espécie de teatralidade inerente ao ser humano. Nestes interesses cruzados Turner e Schechner conheceram a obra um do outro, trocaram correspondências sobre seus trabalhos e discutiram a obra um do outro.

Investigar o conceito de ritual sob esta perspectiva multifacetada propicia a potencialização do entendimento do próprio conceito, pois este não será dado apenas por uma única vertente de pensamento. O conhecimento analisado sob este prisma é tanto mais rico por produzir diálogos entre ideias que em certos momentos são divergentes e em outros convergentes. Esta análise é formadora de ideias tangenciais que se desenvolvem não no centro de um único conhecimento, mas nas margens que permitem ao conceito de ritual transitar livremente entre diversas esferas de conhecimento.

\footnotetext{
2 Este estudo é parte da pesquisa que desenvolvo junto ao Programa de Pós-Graduação Interdisciplinar Performances Culturais da Universidade Federal de Goiás, pesquisa esta que é intitulada Os Conceitos de Ritual, Jogo e Experiência em Richard Schechner e Victor Turner: Análises e Comparações, tendo por orientador o Prof. Dr. Robson Corrêa de Camargo e contando com apoio da Capes através do programa de bolsas Demanda Social.
} 
A seguir iniciarei analisando e definindo o conceito de ritual sob a perspectiva de Victor Turner, levando em conta não somente suas elaborações teóricas, mas subjetividades inerentes ao autor - como aspectos de sua formação que, penso, foram determinantes para a formulação de sua linha de raciocínio. Em seguida analisarei e discutirei a perspectiva de Richard Schechner, que comunga dos postulados de Turner, mas de maneira crítica. Apresentadas as duas vertentes de estudo do conceito de ritual, desenvolverei a análise comparada entre eles, sempre levando em conta certos aspectos subjetivos destes autores - como influências teóricas, aspectos referentes à suas áreas de conhecimento, dentre outros aspectos que se mostraram relevantes para a pesquisa.

\section{Turner, Ritual e os Conceitos Basilares}

Quando se refere à pesquisa desenvolvida a partir da observação e análise dos povos africanos Ndembo, Turner (1974) esclarece o importante fato de que sua formação antropológica inicial fora baseada nos estudos do antropólogo norte americano Lewis Henry Morgan (1818-1881). Turner ressalta que "Morgan, ainda que tivesse registrado fielmente muitas cerimônias religiosas, tinha acentuada aversão a dar ao estudo da religião a mesma penetrante atenção que devotou ao parentesco e à política." (TURNER, 1974, p. 13). O argumento de Morgan para tal aversão, como destaca Turner, era o de que as religiões das tribos pré-letradas não passavam de manifestações que ocupavam-se

tão extensamente com a natureza imaginativa e emocional, por conseguinte com aqueles elementos incertos do conhecimento, que todas as religiões primitivas são grotescas e, até certo ponto, ininteligíveis. (TURNER apud MORGAN, 1974, p.13)

Ao ingressar no campo de pesquisa Turner ainda compartilhava de parte deste preconceito apresentado por Morgan, como faz questão de destacar. Porém o trabalho de campo e o contato com o trabalho do casal Monica (1908-1982) e Godfrey Wilson (1908-1944) causaram uma mudança tanto nos paradigmas quanto nos objetos de pesquisa pretendidos por Turner. $\mathrm{O}$ autor volta-se para o estudo dos rituais dos Ndembo, onde começa a perceber propriedades destes rituais que lhe são esclarecedoras para diversos substratos da vida cotidiana das sociedades pré-letradas. Analisemos então essas propriedades.

Em primeiro lugar, Turner observa que a escolha por realizar certos rituais aqueles os quais não estão diretamente ligados ao calendário da tribo - está, de 
maneira geral, associada a momentos de crise da comunidade. O ritual para os Ndembo, como afirma Turner (1974), está associado à ideia de um retorno ao equilíbrio espiritual de um indivíduo ou grupo que possuía uma perturbação - por exemplo, a infertilidade de uma mulher ou o nascimento de gêmeos. Em vários momentos ele descreve as singularidades referentes aos símbolos rituais das tribos africanas. Aqui o que cabe destacar são as questões pertinentes à definição geral do conceito de ritual, um que possa ser discutido não só em termos do ritual Ndembo, mas em relação aos rituais que concernem à atividade humana.

Em Floresta de Símbolos: Aspetos do ritual Ndembo, Turner (2005) destaca diversos aspectos da riqueza simbólica dos rituais Ndembo e que também são destacados em O Processo Ritual (1974). De maneira geral, o que Turner destaca em ambas as obras é que o ato ritual é uma manifestação povoada de simbologias e representações que podem estar associadas a uma cosmogonia ou a aspectos diretamente ligados ao cotidiano da sociedade. Este aspecto é muito importante para a definição de ritual apresentada por Turner (1974), pois sem a representação simbólica - através de movimentos, máscaras e outros objetos - não é possível, na visão deste autor, o estabelecimento de uma atmosfera ritual, ou seja, de um ambiente diferenciado da realidade cotidiana, onde o ritual se desenvolve.

Para se referir a este momento diferenciado da realidade, Turner se apropria de um termo inicialmente utilizado por Van Gennep (2011). Turner define que o ritual se realiza em um momento que é liminar. Em poucas palavras:

Os atributos de liminaridade, ou de personae (pessoas) liminares são necessariamente ambíguos, uma vez que esta condição e estas pessoas furtam-se ou escapam à rede de classificação que normalmente determina a localização de estados e posições num espaço cultural. As entidades liminares não se situam aqui nem lá; estão no meio e entre as posições atribuídas e ordenadas pela lei, pelos costumes, convenções e cerimonial. (TURNER, 1974, p.117)

Logo o ritual é realizado de modo que nem o tempo, o espaço e nem os indivíduos nele envolvidos são os mesmos da vida cotidiana. Pessoas, tempo e espaço estão sob influência de uma atmosfera simbólica que os ressignifica e transforma seus atributos e status. Este é o momento liminar do ritual, que segundo atribuições de Van Gennep (2011) adotadas por Turner (1974), é precedido por um momento de separação - onde o indivíduo separado de sua vida cotidiana - e posterior a este momento liminar ocorre a agregação - onde o indivíduo se reintegra à sociedade. Porém, é o momento da liminaridade que mais chama a atenção de Turner, este momento de 
margem, este momento onde o indivíduo se desvela em potencialidades. $\mathrm{O}$ momento liminar trás, aos indivíduos e/ou grupos envolvidos no ritual, a possibilidade de transformações que não estão somente na esfera da religiosidade, mas nas camadas mais profundas e mais divergentes das culturas.

O que Turner (1974) observa é que durante este momento liminar onde o indivíduo está despido de suas indumentárias sociais, ou seja, de seu status social, os indivíduos envolvidos no ritual têm uma forte tendência a desenvolver um sentido de grupo muito forte. Isso significa dizer que naquele momento não existem separações de poder entre eles. O estado liminar suscita esta união ou sentimento de igualdade entre os indivíduos, pois neste instante as vaidades relacionadas aos status sociais deixam de existir uma vez que a própria noção de status não se aplica àquele momento. Este sentimento de integração e igualdade é definido por Turner com o termo extraído do latim communitas, que, como ele define: "Prefiro a palavra latina communitas à comunidade, para que se possa distinguir esta modalidade de relação social de uma 'área de vida em comum."' (TURNER, 1974, p.119). Apesar de não se estabelecer uma relação de dependência entre os estados de communitas e liminaridade - ou seja, um não depende do outro para ocorrer - eles têm elementos comuns. Ambos se desenvolvem em momentos que Turner define como "Antiestrutura Social". Estes são instantes transgressores da ordem social estabelecida e caracterizam-se por seu potencial de remoldar a Estrutura Social a partir destes instantes de negação da própria Estrutura.

Segundo o autor define mais adiante a communitas pode ser desenvolvida em outros momentos da vida social que não somente aqueles associados aos rituais, assim como a liminaridade. Estes, liminaridade e communitas, são dois importantes conceitos estudados por Turner quando desenvolve seu famoso modelo de drama ritual $^{3}$ e em seus estudos acerca da performance. Não me estenderei no estudo aprofundado dos conceitos de liminaridade e communitas, pois aí se escreveria um novo trabalho, porém é importante defini-los para o entendimento do conceito de ritual apresentado por Turner nesta etapa de seu trabalho.

\footnotetext{
3 Drama social foi um modelo desenvolvido por Turner a partir das três etapas do rito de passagem de Van Gennep e do modelo de drama da tragédia grega, para explicar a dinâmica das relações sociais. Para mais informações ver TURNER, Victor. Dramas, Campos e Metáforas: Ação simbólica na sociedade humana. Niterói: Editora da Universidade Federal Fluminense, 2008.
} 
Tomando-se por base as considerações anteriores torna-se possível chegar a uma definição do conceito de ritual desenvolvido por Turner ao longo do já citado livro. Então, ritual, segundo a definição deste autor, é uma manifestação religiosa ou ligada a certo grau de sacralização - no sentido amplo do termo - onde por meio de representações simbólicas suscita-se um estado liminar dos indivíduos, o que provoca uma reelaboração simbólica do espaço e tempo, que são relativizados. O atributo liminar do ritual é potencializador da relação de communitas e visa o desencadeamento de uma mudança nos indivíduos e/ou no grupo - esta mudança pode ser referente a uma cura ou a uma elevação de status social, por exemplo.

Tomarei, então, a definição anterior para compreender o conceito de ritual delimitado por Turner. Daí seguirei para a sistematização do conceito de ritual proposto por Schechner que desenvolve horizontes teóricos chave para o entendimento deste e de outros importantes conceitos, como o de performance. Definidas as visões de ambos é que estruturarei o quadro analítico que define as relações de contato, concordâncias e discordâncias estabelecidas entre as obras destes autores e a quais conclusões é possível chegar a partir destas considerações.

\section{Schechner, Ritual e o Encontro Antropológico}

Richard Schechner vem da tradição do teatro, como já afirmado, e ao deslocar seu olhar ampliando-o para os estudos antropológicos ele começa a perceber uma nova abordagem da "ação" humana a qual entende como performance. Apesar de não serem os estudos da performance o foco específico deste trabalho - ainda que o conceito de ritual seja basilar para a discussão da performance tanto para Schechner quanto para Turner - é essencial abordar, ainda que parcialmente, esta temática, pois o conceito de ritual apresentado por Schechner (2012 [2002]) está de todo imbricado em seu conceito de performance.

\section{Em seu texto $O$ Que é Performance? Schechner define que}

Algo 'é' performance quando os contextos histórico e social, a convenção, o uso a tradição, dizem que é. Rituais, jogos e peças, e os papéis da vida cotidiana são performances porque a convenção, o contexto, o uso e a tradição assim dizem. Não se pode determinar o que 'é' performance sem antes referir às culturais específicas. Não existe nada inerente a uma ação nela mesma que a transforma numa performance ou que a desqualifique de ser uma performance. A partir da perspectiva do tipo de teoria da performance que proponho, toda ação é uma performance. Mas da perspectiva da prática cultural, algumas ações serão julgadas performances e outras não; e isto varia de cultura para cultura de período histórico para período histórico. (SCHECHNER, 2011, p.12) 
Nesta perspectiva, qualquer ação, não necessariamente humana, pode ser considerada uma performance, dependendo somente dos padrões da cultura e contexto onde está inserida, ou ainda dos padrões de quem analisa esta ação. É um conceito generalizante que pode incorrer em tautologia, mas esta não é a única definição de performance elaborada por Schechner. O autor apresenta esta generalização para que não haja equívoco para aqueles que se aventurem a estudar performance, destaca-se aí a natureza efêmera e dinâmica deste conceito. Ainda assim, Schechner não se ausenta de tentar sistematizar definições mais precisas sobre o conceito de performance, porém considera a elaboração anterior fundamental aos estudos da performance.

Em outra tentativa de definição - que é um reflexo de seu próprio contexto e cultura - Schechner afirma que

Performances consistem de comportamentos duplamente exercidos, codificados e transmissíveis. Esse comportamento duplamente exercido é gerado através da interação entre o jogo e o ritual. De fato, uma definição de performance pode ser: comportamento ritualizado condicionado/permeado pelo jogo. (SCHECHNER, 2012, p. 49)

Neste trecho podemos perceber o primeiro indicativo da ligação que Schechner faz entre o ritual e a performance. É claro na obra deste autor esta ligação entre os conceitos. Schechner frequentemente se questiona se a origem da performance seria o ritual ou vice-versa, mas a conclusão que chega é que não é possível determinar tal cosmogonia. Para ele, performance e ritual constituem um amalgamado e não é possível determinar quem nasceu primeiro, se o ovo ou a galinha - para fazer alusão ao questionamento tão antigo. E a definição da precedência de um sobre o outro nem de longe é o foco do autor.

Deste imbricado de conceitos, focalizarei daqui para frente os aspectos que Schechner define em relação ao ritual. O autor traz brevemente a questão de que o comportamento ritual humano está ligado a uma manutenção da memória coletiva e individual dos membros de um grupo. Ele ressalta que "Rituais são memórias em ação, codificadas em ações” (SCHECHNER 2012, p. 49). Quando Schechner define ritual como "memórias em ação" ele traz as implicações de uma memória viva, ou seja, que não está somente nas lembranças ou no plano das ideias, mas está no corpo, nos objetos e nos símbolos ou códigos utilizados ao longo do ato ritual.

Outro ponto abordado pelo autor como relevante em relação ao ritual é o fato de que estes são utilizados como meio para lidar com situações difíceis, com os desequilíbrios sociais e pessoais. Neste sentido Schechner também ressalta que os rituais "transformam pessoas, permanente ou temporariamente." (SCHECHNER, 2012, p.50). 
Partindo deste pressuposto, o autor traz a noção de "transporte e transformação". Schechner (2011) afirma que durante o momento liminar do ritual - e aqui se apropria tanto da noção inicial de fase liminar apresentada por Van Gennep (2011) quando do desenvolvimento deste conceito elaborado por Turner (1974) -, o indivíduo é transportado da sua realidade cotidiana para o espaço-tempo ritual onde pode ou não sofrer uma transformação. Schechner elabora que quando em situações de ritual e/ou performance os indivíduos assumem o atributo liminar e estando nesta situação de margem eles são ao mesmo tempo o "não eu" - que é diretamente a negação de si - e o "não não eu" - que através da dupla negativa se reassume consigo mesmo. Partindo desta personalidade binária e dependendo da relação do indivíduo com o ato ritual - se é o xamã que executa ou um iniciado que aspira novo status social, por exemplo - ocorre a transformação onde o indivíduo assume uma nova personalidade.

O ritual, para Schechner (2012), transgride a vida comum, cotidiana. Ainda que estabelecido normativamente dentro das práticas cotidianas de diversos grupos sociais, o ritual em si vai além dos limites estabelecidos para a vida diária. $\mathrm{O}$ ato ritual não é como o hábito, não é um ato repetido apenas por necessidade, apesar de ser realmente complexa a delimitação precisa de quais substratos da vida cotidiana podem ser considerados meramente hábitos e o que de fato é ritual, como faz questão de destacar Schechner (2012). As situações podem se confundir, pois alguns atos cotidianos - como levantar pela manhã - podem tornar-se rituais ou manter-se meramente hábitos dependendo da forma como são executados e encarados pelo indivíduo que os realiza.

Dentro da própria definição de ritual Schechner (2012) acrescenta a diferenciação entre rituais sagrados e seculares. Os rituais sagrados são aqueles desenvolvidos sob uma esfera de religiosidade. Os rituais seculares estão associados aos substratos ditos profanos, ou seja, a política, a vida cotidiana, a economia, as artes. Porém esta separação, como destaca o autor, não pode ser assim tão cartesiana. A exemplo das sociedades pré-letradas, existem culturas onde não se separa arte, política e religião, onde tudo são manifestações do sagrado inerente ao homem.

Faz-se importante ressaltar que para Schechner (2012) o ritual não é um ato somente humano. Destaca o autor que os outros animais também possuem seus rituais. Estes não são manifestações subjetivas e nem possuem uma implicação simbólica como os rituais humanos. São de natureza mais simples e o próprio autor 
chega a questionar se de fato pode-se considerar a existência de um ritual animal ou se é nosso olhar humano ritualístico que confere este caráter às manifestações animais que não passariam da expressão de uma predeterminação genética.

Partindo das definições anteriores podemos concluir que para Schechner o conceito de ritual pode ser sistematizado como uma manifestação, humana ou não, que pode ser de um grau mais simples ou mais elaborado. Em suas manifestações humanas, o ritual pode ser entendido como secular ou sagrado, mas apresenta-se sempre de maneira transgressora da realidade cotidiana e como manifestação da memória individual e/ou coletiva. O momento liminar do ritual constitui-se em um transporte e apresenta um potencial de transformação dos indivíduos envolvidos, este potencial é representado pelo atributo do "não eu" e "não não eu".

Entendendo as linhas gerais do conceito de ritual proposto por Schechner e tendo em vista aquele proposto por Turner, passarei agora para a análise comparada entre as duas proposições deste conceito.

\section{Análise, Comparações e Últimas Considerações}

O livro Performance e Antropologia em Richard Schechner o qual tomei como base para desenvolver o conceito de ritual proposto por Schechner foi publicado originalmente em inglês como capítulos do livro Performance Studies publicado no ano de 2002 e do livro The Future of Ritual: Writings on Culture and Performance de 2004. Turner publica O Processo Ritual em 1969 - original em inglês que é traduzido para o português em 1974. Logo, os escritos que escolhi para analisar o conceito de ritual dos referidos autores são separados por décadas. Décadas de mudanças de paradigmas e de novas reflexões para ambos. Porém não foi inadvertidamente que o fiz.

Por estar ciente da relação de troca, já tão afirmada, estabelecida entre estes dois autores, eu pretendia analisar, para este trabalho, a base do pensamento de ritual proposto por Turner e a ele contrapor um olhar distanciado de seu trabalho, que é oferecido por Schechner. Foi aí que encontrei a riqueza teórica para preencher estas linhas. Desta forma foi possível encontrar os alicerces e as construções feitas sobre elas. Um olhar capaz de ver as partes e de vislumbrar o todo.

Foi possível notar que estes autores apresentam muitas similaridades na elaboração deste conceito, o que em grande parte se deve ao fato de que Schechner se baseia nos estudos de Turner e de Van Gennep - que também orienta o pensa- 
mento de Turner - para elaborar seu conceito de ritual. Ambos situam o ritual em um momento separado da vida cotidiana. Apropriando-se o conceito de liminaridade para elaborar esta cisão. Porém, é no momento de liminaridade que podem ser percebidas as primeiras divergências. Um ponto primário é o entendimento que cada um faz da transformação que ocorre no momento liminar. Turner trata a transformação em termos de "status" e Schechner em termo de personalidade. Isto aponta para a representação que cada um elabora do fato de um indivíduo passar por um processo ritual de transformação. No termo "status", revela-se que para Turner a transformação parece dar-se em uma camada mais exterior, é na forma como a sociedade denomina o sujeito para depois o sujeito vestir-se daquele "status". No termo "personalidade" adotado por Schechner, a relação se desloca ao nível mais pessoal, onde o indivíduo passa a denominar-se de forma diferente. É um desvio de olhar, um que vai do externo para o interno outro que vai do interno para o externo.

Outro desvio passível de análise é que Turner (1974, 2005) dedica-se extensamente à interpretação dos símbolos rituais. Para ele, um ritual é entendido - aí implementando-se a ideia literal de decodificação - ao nível de sua representação simbólica. O ritual é a simbologia que canta, dança, se move. Já Schechner não tem uma preocupação com o símbolo em si, mas com a representação da memória em ação. O que canta, dança e se move para Schechner é a memória de um povo. A ideia de memória está implícita, para Turner, nos símbolos, pois estes são expressões da memória social. Mas a diferença do lugar de onde eles olham para o ritual, um do teatro, outro da antropologia, é forte, apesar de eles estarem no limiar de suas disciplinas. O que Schechner vê são memórias expressas e existentes no corpo, Turner vê símbolos que expressam memórias.

Um elemento observado por Schechner, ao qual Turner não chega a fazer alusão, é o ritual exercido por animais ditos irracionais. Ao estender a esfera do ritual aos outros animais Schechner busca entender a totalidade do ritual como elemento universal e não somente uma manifestação humana. Porém, o mundo como entendemos é expressamente uma representação humana, assim como o entendimento do que denominamos ritual dos outros animais. Mas me parece que o acréscimo feito por Schechner concretiza-se na importância de observar aquilo que é concernente ao ato de ser humano em todos os seus aspectos, inclusive pela negação daquilo que é humano e pelo reconhecimento do que é irracional e inteiramente animal no próprio ser humano. 
No movimento contrário, Turner prefere dedicar-se justamente ao aspecto que nos diferencia radicalmente dos outros animais: a cognição, a capacidade de imaginar, de representar, de produzir símbolos. E são eles, os símbolos rituais, que fascinam o autor, como já afirmado. É um forte indicativo de diferenças de olhar teórico e metodológico destes autores.

Schechner (2012) faz uso constante do termo e das elaborações de Turner sobre liminaridade. Este conceito, o de communitas e a ideia de antiestrutura desenvolvidas pelo antropólogo são largamente utilizadas, reforçadas e amalgamadas ao conceito de ritual, assim como de performance, desenvolvido por Schechner. Porém, gostaria de ressaltar que este autor apresenta uma dura crítica ao modelo de drama ritual apresentado por Turner. Segundo Schechner a apropriação que Turner faz do modelo da tragédia grega aplicado à vida cotidiana é generalista e pouco eficaz para a análise das especificidades, das subjetividades, que são pontos essenciais para o teatrólogo. Schechner não descarta o valor didático do modelo de drama social, porém, acredita que as elaborações sobre liminaridade e communitas atendem melhor às necessidades dos estudos no limiar do teatro e da antropologia onde para ele são desenvolvidos os estudos da performance. Isso mostra que Schechner compartilhava do pensamento basilar de Turner sobre ritual, porém as elaborações posteriores seguem por caminhos diferentes.

São estes desvios no caminho que interessam à minha pesquisa. Os lugares comuns e incomuns e suas justificativas. O conceito de ritual há muito vem sendo discutido por diversos autores e no caso de Schechner e Turner este se revelou um conceito central para o desenvolvimento de seus estudos sobre performance. São desvios que conduzem a um lugar comum e daí a novos desvios. Este elemento de intercruzamento das obras e ideias de Schechner e Turner traz riqueza aos estudos do conceito de ritual. Visto sob este prisma de multiplicidade o conceito de ritual ganha novo fôlego para discussão. Entendo que os encontros entre antropologia e teatro não começaram e não iram terminar com Turner e Schechner, mas as teias de conhecimento que eles tecem me conduziram, e conduzirão muitos outros, às bases inter, multi e transdisciplinares que produzem os novos saberes.

\section{Referências}

LIGIÉRO, Zeca. Performance e Antropologia de Richard Schechner. Rio de Janeiro: Mauad, 2012.

TURNER, Victor. O Processo Ritual Estrutura e Anti Estrutura. São Paulo: Vozes, 1974. Floresta de Símbolos: aspectos do ritual Ndembu. Rio de Janeiro: Eduff, 2005

Dramas, Campos e Metáforas: Ação simbólica na sociedade humana. Niterói: Editora da Universidade Federal Fluminense, 2008. 
SCHECHNER, Richard. Performance Studies: An Introduction. Routledge, 2002. Págs. 45-78.

O que é performance? Tradução de R.L. Almeida, publicado sob licença creativa commons, classe3. Abril de 2011. Do original em ingles SCHECHNER, Richard. Performance studies: an introduccion, second edition. New York \& London: Routledge, 2002. p. 28-51. Disponível em:

http://performancesculturais.emac.ufg.br/uploads/378/original_O_QUE_EH_PERF_ SCHECHNER.pdf

Performers e Espectadores:Transportados e Transformados. In Revista Moringa Artes do Espetáculo. Vol 2. N1. 2011.

The Future of Ritual: Writings on Culture and Performance. Routledge: New Fatter Lane, 2004.

VAN GENNEP, Arnold. Os Ritos de Passagem. Tradução Mariano Ferreira. 2 edição. Petrópolis: Vozes, 2011. 